\title{
Temperatura e embalagem para abóbora minimamente processada
}

\author{
Temperature and packaging of minimally processed pumpkin (Curcubita moschata)
}

\author{
Ana Veruska Cruzda SILVA ${ }^{1 *}$, Douglas Sodré Nunes OLIVEIRA², Paula YAGUIU², \\ Marcelo Augusto Gutierrez CARNELOSSI ${ }^{2}$, Evandro Neves MUNIZ ${ }^{1}$, Narendra NARAIN ${ }^{2}$
}

\section{Resumo}

O objetivo deste trabalho foi avaliar temperaturas de armazenamento e embalagens para abóbora minimamente processada. Pedaços de abóbora foram cortados em tamanho de $5 \times 10 \mathrm{~cm}$, embalados em bandejas de poliestireno recobertas com filme polivinilcloreto e em embalagem de polietileno de alta densidade a vácuo. O produto foi mantido a 5 e $10{ }^{\circ} \mathrm{C}$ por um período de 12 dias. A cada três dias avaliou-se o teor de sólidos solúveis, acidez total titulável, $\mathrm{pH}$, vitamina $\mathrm{C}$ e coloração. Os resultados mostraram não haver diferenças significativas entre as duas temperaturas de refrigeração utilizadas na conservação da abóbora. Entretanto, a embalagem com filme PVC permitiu maior conservação dos atributos de qualidade da abóbora até o $9^{\circ}$ dia, com exceção da cor, que sofreu menores alterações quando usada embalagem a vácuo.

Palavras-chave: Curcubita moschata; processamento mínimo; qualidade.

\begin{abstract}
The present work aimed to evaluate the efficiency of different storage temperatures and packing materials for pumpkin fresh cuts. Pumpkin cuts of $5 \times 10 \mathrm{~cm}$ were packed in polystyrene trays covered with polivynilchloride film or in vacuum high density polyethylene bags. The trays and bags were kept at 5 and $10{ }^{\circ} \mathrm{C}$ for 12 days. Soluble solids, total titratable acidity, $\mathrm{pH}$, vitamin $\mathrm{C}$, and color of pumpkin cuts were evaluated every 3 days. The different temperatures did not affect the storage of the pumpkins. However, packaging with PVC film allowed a longer conservation by keeping the pumpkin quality attributes up to the 9th day, except for the color which undergone minor alterations when stored within a vacuum pack.
\end{abstract}

Keywords: Curcubita moschata; minimum processing; quality.

\section{Introdução}

A tendência de mudanças nos hábitos alimentares da população mundial mostra um aumento discreto no consumo de frutas e hortaliças, além de uma busca constante por alimentos de conveniência, que exija tempo reduzido de manuseio e preparo sem, no entanto, alterar suas características sensoriais e nutricionais originais. Assim, a abóbora (Cucúrbita moschata Duch), que é uma olerícola de grande aceitação em todo o País, especialmente na região Nordeste, encontra no processamento mínimo, uma forma eficiente de aumentar o consumo e o valor agregado ao produto.

Frutas e hortaliças minimamente processadas mantêm seus tecidos vivos e não exibem a mesma resposta fisiológica que um tecido intacto (WILEY, 1994). Segundo Cantwell (1992), algumas consequências de estresse causado pelo processamento são o desenvolvimento de sabores e odores desagradáveis e amaciamento dos tecidos. Esses produtos são mais perecíveis e apresentam um aumento da taxa respiratória e produção de etileno, aumentando a atividade enzimática devido à ruptura de muitas células (CHITARRA, 1998). O processamento mínimo da abóbora envolve descasque e cortes. Além disso, são lavadas e submetidas a processos de sanitização.

$\mathrm{O}$ armazenamento refrigerado tem importante papel na conservação de alimentos, retardando as transformações provocadas por reações bioquímicas e disseminação de bactérias e fungos
(VISSOTO et al., 1999). Arruda et al. (2003a) verificaram que a melhor temperatura para manutenção da qualidade em melão rendilhado foi $3{ }^{\circ} \mathrm{C}$. Para manga, Allong et al. (2000) constataram que melhor seria $5{ }^{\circ} \mathrm{C}$ e, para abóbora, Sasaki et al. (2004) indicaram as temperaturas de 1 e $5^{\circ} \mathrm{C}$.

O uso da atmosfera modificada é uma prática efetiva no prolongamento da vida útil, havendo respostas diferentes, dependendo da espécie. Segundo Arruda et al. (2003b), um aspecto negativo do uso de embalagens é o aumento da temperatura e, por isso, o ideal é que seu uso esteja associado a baixas temperaturas de armazenamento.

Dentre os vários materiais que têm sido utilizados para acondicionamento de frutas e hortaliças, incluem-se o polivinilcloreto (PVC) e o polietileno de alta e de baixa densidade. De acordo com Zagory; Kader (1988), é importante o conhecimento das características respiratórias e condições gasosas ótimas do produto para se poder selecionar um filme.

Apesar do avanço tecnológico e dos diversos estudos já realizados com produtos vegetais minimamente processados, em relação às Cucurbitáceas, os conhecimentos são ainda muito restritos ao melão (Cucumis melo L.), existindo uma lacuna na literatura consultada no que diz respeito ao processamento

Recebido para publicação em 22/10/2007

Aceito para publicação em 3/1/2009 (002941)

${ }^{1}$ Embrapa Tabuleiros Costeiros, Av. Beira Mar, 3250, CP 44, CEP 49025-040, Aracaju - SE, Brasil, E-mail: anaveruska@cpatc.embrapa.br

${ }^{2}$ Departamento de Engenharia Agronômica, Universidade Federal de Sergipe - UFS, Av. Marechal Rondon, s/n, Jardim Rosa Elze, CEP 49100-000, São Cristovão - SE

${ }^{*}$ A quem a correspondência deve ser enviada 
mínimo da abóbora. Segundo Sasaki (2005), a abóbora é uma hortaliça que tem apresentado grande potencial de expansão no mercado de vegetais minimamente processados, visto que são frutos de grande dimensão e que apresentam dificuldades quanto a sua comercialização, armazenamento e manuseio, ocasionando muitas perdas. Segundo o mesmo autor o processamento mínimo de abóbora poderia aumentar a comercialização e agregar valor ao produto.

O objetivo deste trabalho foi avaliar temperaturas de armazenamento e embalagens para abóbora minimamente processada.

\section{Material e métodos}

O experimento foi desenvolvido no Laboratório de Tecnologia de Alimentos da Universidade Federal de Sergipe. Pedaços de abóbora foram cortados no tamanho de $5 \times 10 \mathrm{~cm}$ e imersos em água resfriada a $5{ }^{\circ} \mathrm{C}$, contendo $150 \mathrm{mg} \cdot \mathrm{L}^{-1}$ de cloro ativo, por 10 minutos. Em seguida foi feito um enxágue em água a $5^{\circ} \mathrm{C}$, contendo $3 \mathrm{mg} . \mathrm{L}^{-1}$ de cloro ativo, para retirada de excesso de sanitizante (Dicloro S. Triazinatriona Sódica Dihidratada). A centrifugação ocorreu a $1290 \times$ g por um minuto. As embalagens utilizadas foram bandejas de poliestireno revestidas com Polivinilcloreto (PVC) e embalagem de polietileno de alta densidade a vácuo.

As amostras foram armazenadas em câmaras frias, a temperaturas de 5 e $10{ }^{\circ} \mathrm{C}$ por um período de 12 dias. A cada três dias avaliou-se:

a) teor de sólidos solúveis (SS): utilizou-se um refratômetro manual, modelo WYA ABBE, conforme normas da AOAC (1992). Os resultados foram expressos em ${ }^{\circ} \mathrm{Brix}$.

b) acidez total titulável (ATT): foi determinada por titulação, com solução de $\mathrm{NaOH} 0,1 \mathrm{~N}$ e fenolftaleína a $1 \%$ como indicador, e os valores expressos em porcentagem de ácido cítrico.

c) $\mathrm{pH}$ : a leitura foi realizada com um potenciômetro eletrônico, utilizando-se cinco gramas de polpa diluída em $50 \mathrm{~mL}$ de água destilada.

d) vitamina C: foi determinada através da técnica de titulação com DCBIB (Diclorofenolendofenol) e os valores expressos em mg de vit. C. $100 \mathrm{~g}^{-1}$ de polpa.

e) coloração: utilizou-se um colorímetro MINOLTA modelo CR-10. Realizaram-se duas leituras em cada polpa. As leituras foram realizadas apontando-se o sensor do aparelho para a superfície da polpa da abóbora, avaliando-se os seguintes parâmetros: $\mathrm{L}^{*}$, que indica luminosidade ou brilho e varia do claro para o escuro; $\mathrm{a}^{*}$, que indica a cromaticidade no eixo da cor verde (-) para vermelha $(+)$; e $b^{*}$, que indica a cromaticidade no eixo da cor azul (-) para amarela (+). As leituras foram realizadas de acordo com Palou et al. (1999).

O delineamento experimental utilizado foi inteiramente casualizado, em esquema fatorial $2 \times 2 \times 6$ (dois tipos de embalagens, bandejas de poliestireno revestidas com Polivinilcloreto (PVC) e embalagem de polietileno de alta densidade a vácuo; duas temperaturas de armazenamento, 5 e $10^{\circ} \mathrm{C}$ e cinco tempos de avaliação $0,3,6$, 9 e 12 dias), com três repetições. Os resultados foram analisados estatisticamente pelo programa SAS ${ }^{\oplus}$ System, no qual foram submetidos à análise de variância e teste de Tukey a 5\%.

\section{Resultados e discussão}

Uma perda de cor, nos pedaços de abóbora, foi observada pelo índice de escurecimento (IE) conforme Figura 1, principalmente nos tratamentos utilizando PVC, que apresentaram algumas áreas mais claras (brancas). A embalagem a vácuo permitiu uma melhor manutenção da cor, apesar das variações ocorridas. O uso de aditivos para preservação da coloração de produtos minimamente processados tem sido alvo de estudo para muitos pesquisadores. Em melão, Lamikanra, Watson (2000) verificaram que a utilização de ácido ascórbico preservou a coloração na cv. Cantaloupe por até 25 dias, a $4{ }^{\circ} \mathrm{C}$.

No presente trabalho, o aspecto visual foi determinante para a continuação do experimento, sendo que aos 12 dias foi verificado uma alta incidência de manchas escuras e alto índice de injúria pelo frio (60\%). Moretti et al. (2001) verificaram que batata-doce minimamente processada armazenada a $3{ }^{\circ} \mathrm{C}$ sob atmosfera modificada passiva apresentou escurecimento significativo, justificado pelo elevado teor de compostos fenólicos que atuam diretamente no escurecimento enzimático.

Os sintomas mais comuns da injúria pelo frio, em abóbora minimamente processada, foram o escurecimento e o afundamento de pequenas áreas da polpa. Além disso, o amadurecimento dos frutos foi retardado e apresentaram uma coloração manchada. Houve um pico na densidade de escurecimento (DE) no $3^{\circ}$ dia de armazenamento, seguido de uma diminuição pelo surgimento do branqueamento, e um escurecimento entre o $6^{\circ}$ e o $12^{\circ}$ dia nos frutos embalados com PVC, independente da temperatura, por consequência da injúria pelo frio (Figura 1).

Análises subjetivas da cor e registros fotográficos indicaram que a incidência da injúria pelo frio ocorreu de maneira expressiva na superfície dos pedaços que ficaram com o lado para cima. Estes resultados podem ser atribuídos ao aumento da atividade da enzima poligalacturonase, que hidrolisa componentes da parede celular, como as substâncias pécticas, responsáveis pela firmeza da polpa (KARAKURT; HUBER, 2002). Os componentes que constituem a parede celular do tecido podem ser formados através de rotas alternativas induzidas pela enzima fenilalanina amonialiase, em resposta ao estresse fisiológico do frio no tecido (SILVA et al., 2003).

Os teores médios totais de sólidos solúveis (SS) variaram de 9,83 a $10,38^{\circ} \mathrm{Brix}$, verificando maiores concentrações quando embaladas com PVC e mantidas a $10^{\circ} \mathrm{C}$, conforme Tabela 1 . Ao contrário do que ocorre com a maioria dos produtos minimamente processados, a abóbora não apresentou um aumento linear no teor de sólidos solúveis. Entretanto, esse fato é comum devido à perda de água do produto, que pode ocorrer logo após o processamento. No $6^{\circ}$ dia houve uma tendência a aumento, diminuindo no $9^{\circ}$ dia e voltando a revelar-se no $12^{\circ}$ dia. Em melão, Arruda et al. (2003a) encontraram valores de SS progressivos e que variaram entre 11,64 e 12,32. Entretanto, Shellie, Saltveit (1993) discordam desse comportamento progressivo e verificaram um 
comportamento constante do teor de sólidos solúveis de melões rendilhados durante todo o período de armazenamento.

Em relação à ATT e ao $\mathrm{pH}$, os valores encontrados não apresentaram diferença na média final entre as diferentes embalagens ou temperaturas, havendo, entretanto, variação entre as embalagens no $3^{\circ}$ e $9^{\circ}$ dia. O tempo de armazenamento influenciou significativamente o teor de ATT, havendo aumento

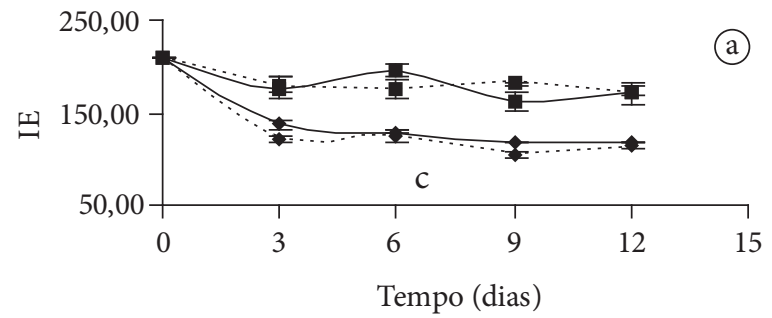

$$
\begin{aligned}
& \longrightarrow \text { IE }\left(5^{\circ} \mathrm{C}\right) \text { Vácuo } \\
& \cdots \cdots
\end{aligned}
$$

na sua concentração final. As variações nos teores médios de ATT são mostradas na Tabela 1 . As curvas indicam um acréscimo da ATT até o $6^{\circ}$ dia, com exceção dos embalados
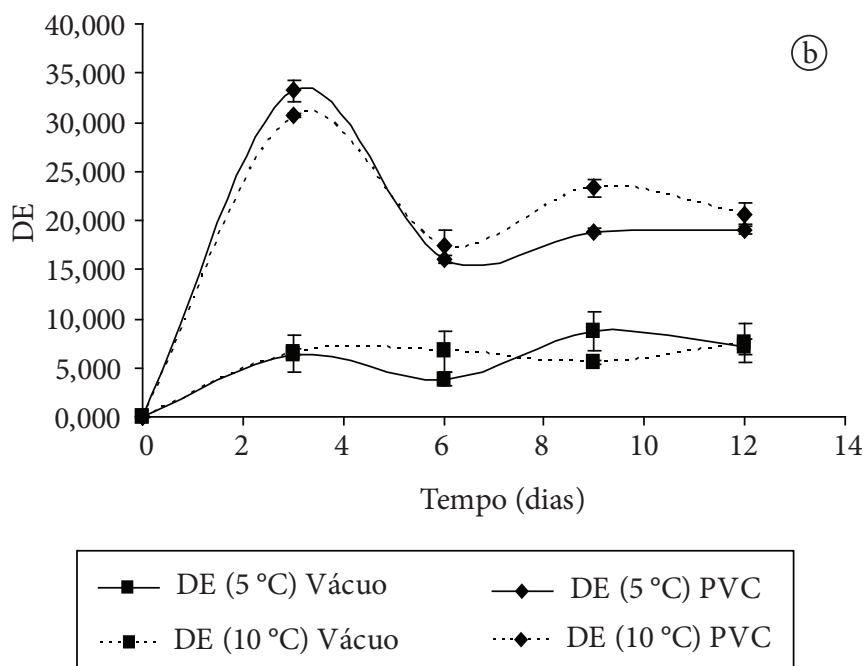

Figura 1. Índice (a) e densidade (b) de escurecimento em abóbora minimamente processada.

Tabela 1. Valores médios do teor de sólidos solúveis (SS); acidez total titulável (ATT); pH e vitamina C de abóbora minimamente processada e armazenada em diferentes embalagens e em diferentes temperaturas.

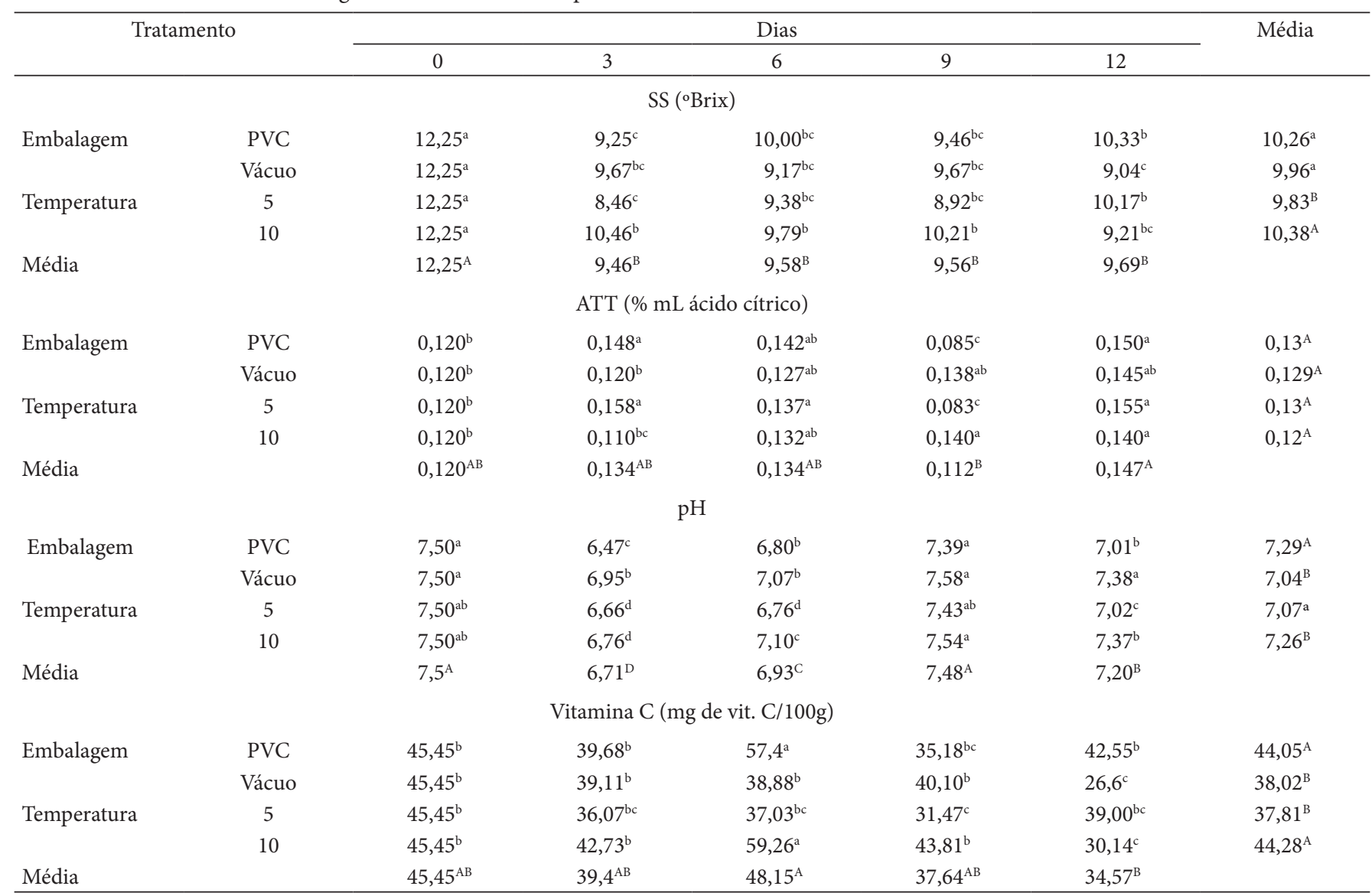

Letras minúsculas distintas nas linhas para embalagem ou temperatura apresentam diferença estatística $(\mathrm{P}<0,05)$; Letras maiúsculas distintas nas linhas para o tempo de armazenamento e na coluna para embalagem ou temperatura apresentam diferença estatística $(\mathrm{P}<0,05)$. 
a vácuo e mantidos a $10^{\circ} \mathrm{C}$. O acréscimo na ATT que ocorreu até o $6^{\circ}$ dia implicou em decréscimo no $\mathrm{pH}$, pois as variações no $\mathrm{pH}$ traduzem as variações na ATT (TEISSON, 1979). Verificou-se, em todos os tratamentos, que os valores de $\mathrm{pH}$ da abóbora minimamente processada tenderam a se elevar após o nono dia de armazenamento. Esse aumento no $\mathrm{pH}$ tem sido observado em diversos produtos minimamente processados. Entretanto, como esse efeito não é bem conhecido, acredita-se que essa elevação seja uma consequência dos efeitos do metabolismo normal de $\mathrm{CO}_{2}$ ou reação direta do tecido vegetal, eliminando o $\mathrm{CO}_{2}$ do interior de seus tecidos para os vacúolos ou ambiente e, assim, diminuindo a acidez causada por ele (KADER, 1986).

Para o teor de vitamina C, não foi encontrada interação significativa entre embalagem e temperatura, havendo, porém, entre embalagem e tempo, e entre temperatura e tempo. $\mathrm{O}$ tempo de armazenamento influenciou significativamente o teor de vitamina $\mathrm{C}$, ocorrendo as maiores perdas no sexto dia de armazenamento e os menores, no décimo segundo dia. Quanto às embalagens, a de PVC apresentou maior valor total de Vitamina C (Tabela 1). Observou-se também que, quanto mais alta a temperatura de armazenamento, maior foi a conservação do teor de ácido ascórbico nos tratamentos. Esse comportamento também foi verificado em abacaxi minimamente processado e armazenado a 3, 6 e $9{ }^{\circ} \mathrm{C}$ (SARZI; DURIGAN, 2002).

\section{Conclusões}

A temperatura não influenciou a qualidade de abóbora minimamente processada. Ao contrário, a embalagem apresentou influência significativa, sendo que o PVC permitiu maior conservação dos atributos de qualidade da abóbora, com exceção da cor, que sofreu menores alterações quando usada embalagem a vácuo.

\section{Referências bibliográficas}

ALLONG, R.; WICKHAM, L. D.; MOHAMMED, M. The effect of cultivar, fruit ripeness, storage temperature and duration on quality of fresh-cut mango. Acta Horticulturae, v. 509, n. 2, p. 487-494, 2000.

ASSOCIATION OF OFFICIAL ANALYTICAL CHEMISTRY - AOAC. Official Methods as Analysis of the Association of Official Analytical Chemists. Washington, 1992.

ARRUDA, M. C. et al. Temperatura de armazenamento e tipo de corte para melão minimamente processado. Revista Brasileira de Fruticultura, v. 25, n. 1, p. 74-76. 2003a.

ARRUDA, M. C. et al. Qualidade de melão minimamente processado armazenado em atmosfera modificada passiva. Horticultura Brasileira, v. 21, n. 4, p. 665-659, 2003 b.
CANTWELL, M. Postharvest handling systems: minimally processed fruits and vegetables. In: KADER, A. A. (Ed.). Postharvest technology of horticultural crops. Oakland: University of Califórnia, 1992. p. 277-281.

KADER, A. A. Biochemical and physiological basis for effects of controlled and modified atmospheres on fruits and vegetables. Food Technologics, v. 40, n. 5, p. 99-104, 1986.

KARAKURT, Y.; HUBER, D. J. Activities of several membrane and cell-wall hydrolases, ethylene biosynthetic enzymes, and cell wall polyuronide degradation during low-temperature storage of intact and fresh-cut papaya (Carica papaya) fruit. Postharvest Biology and Technology, v. 24, n. 2, p. 1-11, 2002.

LAMIKANRA, O.; CHEN, O.; BANKS, D. Biochemical and microbial changes during the storage of minimally process Cantaloupe. Journal of Agriculture and food chemistry, v. 48, n. 12, p. 5955-5961, 2000.

MORETTI, C. L.; MAROVELLI, W. A.; SILVA, W. L. C. Respiratory activity and browning of minimally processed sweet potatoes. Stuart: Florida State Horticultural Society, 2001. p. 150-152.

PALOU, E. et al. Polyphenoloxidase activity and calow of blanched and high hydrostatic pressure treafed banana puree. Journal Food Science, v. 64, n. 1, p. 42-45, 1999.

SARZI, B.; DURIGAN, J. F. Avaliação física e química de produtos minimamente processados de abacaxi 'Pérola'. Revista Brasileira de Fruticultura, v. 24, n. 2, p. 333-337, 2002.

SASAKI, F. F. et al. Taxa respiratória e produção de etileno de abóboras minimamente processadas em função da temperatura de armazenamento. Horticultura Brasileira, v. 22, n. 2, Supl., 2004.

SASAKI, F. F. Processamento mínimo de abóbora (Cucúrbita moschata Duch.): alterações fisiológicas, qualitativas e microbiológicas. 2005. 145 p. Dissertação (Mestrado em Fisiologia de Bioquímica de Plantas) - Escola Superior de Agricultura "Luiz de Queiroz", Universidade de São Paulo, Piracicaba, 2005.

SHELLIE, K. C.; SALTVEIT Jr., M. E. The lack of a respiratory rise in muskmelon fruti ripening on the plant challenges the definition of climacteric behaviour. Journal of Experimental Botany, v. 44, n. 265, p. 1403-1406, 1993.

SILVA, H. R. F. et al. Relação entre o escurecimento e a atividade da enzima fenilalanina amonialiase em mamão (Carica papaya L.) armazenado sob refrigeração. In: SIMPÓSIO DO PAPAYA BRASILEIRO, 2003, Vitória. Anais... Vitória: Incaper, 2003. p. 681-684.

TEISSON, C. Le brunissement interne de Ananas. Fruits, v. 34, n. 4, p. $245-161,1979$.

VISSOTO, F. Z.; KIECBUSH, T. G.; NEVES FILHO, L. C. Préresfriamento de frutas e hortaliças com ar forçado. Boletim da Sociedade Brasileira de Ciência e Tecnologia de Alimentos, v. 33, n. 1, p. 106-114, 1999.

WILEY, R. C. Minimally processed refrigerated fruits and vegetables. New York: Champman \& Hall, 1994. 368 p.

ZAGORY, D.; KADER, A. A. Modified atmosphere packing of fresh produce. Food Technology, v. 42, n. 9, p. 70-77, 1988 